\title{
The A2UFood Project-Avoidable and Unavoidable Food Wastes: A Holistic Managing Approach for Urban Environments ${ }^{+}$
}

\author{
Christina Chroni ${ }^{1, *}$, Katia Lasaridi ${ }^{1}$, Nikos Stylianidis ${ }^{2}$, Kelly Velonia ${ }^{3}$, Thrassyvoulos Manios ${ }^{4}$, \\ Ioannis Daliakopoulos ${ }^{4}$, Christos Tsompanidis ${ }^{5}$, Gerold Hafner ${ }^{6}$, Manolis Skarvelakis ${ }^{7}$ \\ and Zacharenia Drosou ${ }^{7}$ \\ 1 Department of Geography, Harokopio University, 17671 Kallithea, Greece; klasaridi@hua.gr \\ 2 ESDAK (United Association of Solid Waste Management in Crete), Archiepiskopou Makariou 22, \\ 71202 Heraklion, Greece; nstyl@esdak.gr \\ 3 Department of Materials Science and Technology, University of Crete, University Campus Voutes, \\ Heraklion, 71003 Crete, Greece; velonia@materials.uoc.gr \\ 4 Department of Agriculture, Hellenic Mediterranean University, 71410 Heraklion, Greece; \\ tmanios@hmu.gr (T.M.); idaliak@hua.gr (I.D.) \\ 5 ENVIROPLAN S.A., 23 Perikleous \& Iras str., 15344 Gerakas-Athens, Greece; ct@enviroplan.gr \\ 6 Institute for Sanitary Engineering, Water Quality and Solid Waste Management, University of Stuttgart, \\ Bandtäle 2, 70569 Stuttgart, Germany; gerold.hafner@iswa.uni-stuttgart.de \\ 7 Municipality of Heraklion, Agiou Titou 1, 71202 Heraklion, Greece; skarvelakis-m@heraklion.gr (M.S.); \\ drosou@heraklion.gr (Z.D.) \\ * Correspondence: chroni@hua.gr \\ + Presented at TERRAenVISION 2019, Barcelona, Spain, 2-7 September 2019. \\ Published: 4 June 2020
}

\begin{abstract}
Food waste is a stream with multiple social, economic, and environmental implications, generated throughout all the life cycle stages of food. Among these stages, in developed and top touristic destination countries such as Greece, the role of the hospitality sector (i.e., restaurants, hotels, catering, etc.) in food waste generation is particularly significant. Against this background, the A2UFood project introduces a holistic management scheme in the municipality of Heraklion (Crete, Greece), in which all aspects of reduction, reuse, and recycling of food waste are included. The project seeks to implement the circular economy concept into daily practice, through a series of actions which preserve natural resources, support local communities, and create new value chains. More specifically, the holistic management scheme of the A2UFood project progresses towards three innovative directions: (i) Surplus food of high quality, from hotels and restaurants, will be redirected to people in need, through the establishment and operation of the "2nd opportunity" restaurant; (ii) Food waste from the hospitality sector will be directed to bioplastic production units; and iii. Home and community composting will be promoted and supported, as an option for the management of household food waste. To achieve the goals of the A2UFood project, an Information Campaign ("Food Save Share"), training workshops-seminars, and two smart tools (i.e., the Digital Food Waste Prevention Tool and the Resource Management Food Tool, for households and kitchen managers, respectively) have been developed.
\end{abstract}

Keywords: food waste prevention; circular economy 
Acknowledgments: The A2UFood Project (UIA02-115) is co-funded by the European Regional and Development Fund through the Urban Innovative Actions (UIA) Initiative.

(C) 2020 by the authors. Licensee MDPI, Basel, Switzerland. This article is an open access article distributed under the terms and conditions of the Creative Commons Attribution (CC BY) license (http://creativecommons.org/licenses/by/4.0/). 